\title{
Assessing the Short-term Effects of Endotracheal Intubation on Voice Change and Acoustic Parameters: A Prospective Observational Study
}

\author{
Anagha A Joshi ${ }^{1}$, Nikhil R Dhorje ${ }^{2}$, Renuka A Bradoo ${ }^{3}$, Kanchan Rupwate ${ }^{4}$, Devika S Arora ${ }^{5}$
}

\begin{abstract}
Aims and objectives: (1) To examine vocal symptoms and acoustic changes perceived within 24 hours after endotracheal intubation and (2) to find the association between these changes and endotracheal tube (ET) parameters and determine which parameter affects voice the most.

Materials and methods: A prospective analysis of 75 patients was done. They were examined preoperatively, and 2 and 24 hours postoperatively. The vocal symptoms of hoarseness, vocal fatigue, loss of voice, throat clearing (hawking), globus pharyngeus, throat pain, and the acoustic variables mainly average fundamental frequency, shimmer, harmonic noise ratio (HNR), and maximum phonation time (MPT) were assessed. The ET parameters considered were duration of anesthesia, number of attempts at intubation, size of the tube, ET cuff volume, and mean cuff pressure. Results: Approximately $60 \%$ of patients with cuff volume above $3 \mathrm{~cm}^{3}$ and $80 \%$ of patients with more than two intubation attempts developed postoperative vocal fatigue, while $70 \%$ with mean cuff pressure above $20 \mathrm{~cm}$ of water developed postoperative hawking.

Conclusion: The ET parameters, mean cuff pressure, and ET cuff volume are the most important variables that are associated with the increase in vocal symptoms. An increase in the value of these parameters is associated with more postoperative discomfort.

Keywords: Acoustic analysis, Endotracheal tube, Hoarseness, Intubation, Jitter, Larynx, Shimmer, Vocal folds, Voice.

International Journal of Phonosurgery \& Laryngology (2021): 10.5005/jp-journals-10023-1191
\end{abstract}

\section{INTRODUCTION}

Most of the major surgical procedures in ENT require endotracheal intubation to provide general anesthesia (GA) and intermittent positive pressure ventilation (IPPV). Voice changes occurring after endotracheal intubation are a common finding which leaves patients with unpleasant postoperative recovery and overall experience. By selecting proper endotracheal tube (ET) parameters, this can be reduced to a great extent. Most of the voice changes associated with endotracheal intubation including acoustic parameters are short-lasting and baseline recovery occurs within a period of 24 hours without any long-lasting sequelae in the majority of cases. ${ }^{1,2}$ There have been studies to investigate the laryngotracheal morphological and histological changes associated with prolonged intubation. ${ }^{1-3}$

The purpose of this study is to (1) assess the immediate changes in the voice and acoustic parameters occurring after endotracheal intubation, and (2) to correlate these changes with the endotracheal tube and acoustic parameters, and (3) to find the acoustic parameter which is affected most.

\section{Materials and Methods}

A prospective analysis was conducted on patients admitted for routine ENT surgeries at our tertiary referral center. A total of 86 patients were included in the study after taking written, informed, and valid consent. Out of 86,48 patients were males (56\%), while 38 patients were females (44\%). The patients ranged from 19 to 68 years, with an average of 37 years. All the patients were subjected to rigid laryngoscopic examination prior to surgery to exclude any vocal fold lesions and/or morphological abnormalities in the vocal folds as well as postoperative vomiting and/or retching. All the surgeries related to the vocal folds and neck surgeries that
1,3,5 Department of ENT, Lokmanya Tilak Municipal Medical College and General Hospital, Mumbai, Maharashtra, India

${ }^{2}$ Department of ENT and Head-Neck Surgery, Lokmanya TilakMunicipal Medical College and General Hospital, Mumbai, Maharashtra, India

${ }^{4}$ Department of Anesthesia, Lokmanya Tilak Municipal Medical College and General Hospital, Mumbai, Maharashtra, India

Corresponding Author: Nikhil R Dhorje, Department of ENT and HeadNeck Surgery, Lokmanya Tilak Municipal Medical College and General Hospital, Mumbai, Maharashtra, India, Phone: +91 9404739387, e-mail: nikhildhorje43@gmail.com

How to cite this article: Joshi AA, Dhorje NR, Bradoo RA, et al. Assessing the Short-term Effects of Endotracheal Intubation on Voice Change and Acoustic Parameters: A Prospective Observational Study. Int J Phonosurg Laryngol 2021;11(1):21-24.

Source of support: Nil

Conflict of interest: None

require dissection in the proximity of recurrent laryngeal nerves like thyroid and parathyroid surgeries were also excluded. Single senior anesthetist has done all the intubations to minimize chances of interpersonal variations. The anesthetist has evaluated the patients preoperatively for any difficult laryngeal exposure while intubating using modified Mallampati classification (MMC). ${ }^{4}$ All the patients were evaluated preoperatively in the morning before surgery, immediately 2 hours after the surgery, and 24 hours following the surgery. Every time the analysis of voice was done in a soundproof room, to minimize chances of surrounding ambient noise distorting the readings. The recording was done with the patient in seating position in a chair, both during the preoperative and postoperative time. After 24 hours, 75 patients ( 42 males and 33 females) remained 
in the study for evaluation, as 7 patients had vomited in the postoperative period, while 4 patients had an excessive cough in the postoperative period. Patients were asked about the presence or absence of the following vocal complaints: hoarseness, throat pain, vocal fatigue, loss of voice, throat clearing, and globus pharyngeus (foreign body sensation in the throat). The acoustic analysis of the voice was done using "Dr Speech voice analysis software" (Seattle, Washington). A microphone was placed at a distance of $15 \mathrm{~cm}$ from the mouth of the patient to record the vocal signal directly into the system. The average fundamental frequency, shimmer, harmonic noise ratio (HNR), and jitter were measured by asking the patient to sustain vowel "ah" for 3 seconds. To calculate the maximum phonation time (MPT), they were instructed to hold the vowel /a/ as long as they could, after taking a maximal inhalation. All the patients underwent general anesthesia with the insertion of an ET through the oral cavity. The following parameters were recorded: the size of the endotracheal tube, number of attempts at intubation, duration of anesthesia, ET cuff volume, and mean cuff pressure, which was calculated as an average of the cuff pressure at intubation and extubation (Table 1).

\section{Results}

86 patients were evaluated preoperatively of which 75 remained for the 24-hour evaluation. The age of the participants ranged

Table 1: Parameters assessed for the study

\begin{tabular}{|c|c|c|}
\hline Vocal symptoms & Acoustic parameters & $\begin{array}{l}\text { Endotracheal tube } \\
(E T) \text { parameters }\end{array}$ \\
\hline Hoarseness & $\begin{array}{l}\text { Maximum phonation } \\
\text { time (seconds) }\end{array}$ & Size of the tube \\
\hline Throat pain & $\begin{array}{l}\text { Average fundamental } \\
\text { frequency }(\mathrm{Hz})\end{array}$ & $\begin{array}{l}\text { Number of attempts } \\
\text { at intubation }\end{array}$ \\
\hline Vocal fatigue & Shimmer (\%) & ET cuff volume $\left(\mathrm{cm}^{3}\right)$ \\
\hline Loss of voice & Harmonic noise ratio $(\mathrm{dB})$ & $\begin{array}{l}\text { Mean cuff pressure } \\
\text { (cm of water) }\end{array}$ \\
\hline Throat clearing & Jitter (\%) & $\begin{array}{l}\text { Duration of } \\
\text { anesthesia (hours) }\end{array}$ \\
\hline Globus pharyngeus & & \\
\hline
\end{tabular}

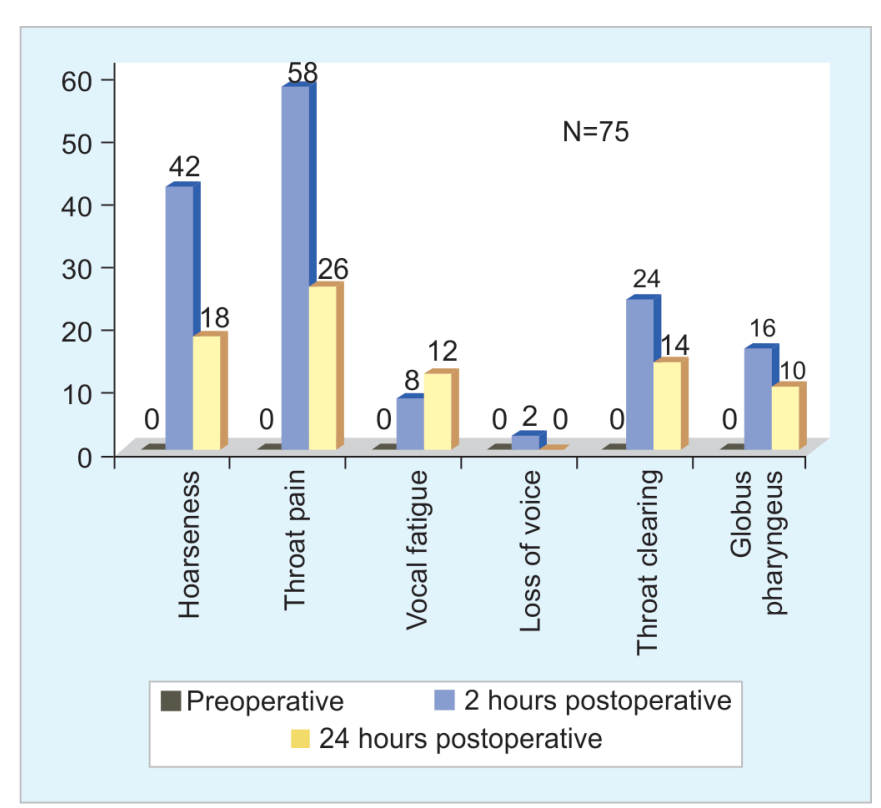

Fig. 1: Vocal symptoms of the patients (values are in percentage) from 16 to 70 years, with a mean of $38.2 \pm 3.2$. There were $68.6 \%$ (59) males and $31.3 \%$ (27) females in the study. The duration of anesthesia ranged between 120 minutes and 420 minutes. The ET sizes used for intubation ranged from sizes 6 to 7.5 for females and 7 to 8.5 for males.

There was a significant increase in the incidence of each of the vocal symptoms; namely, hoarseness, throat pain, vocal fatigue, throat clearing, and globus pharyngeus, 2 hours after GA, except for the loss of voice. However, the frequencies of these symptoms decreased within 24 hours. None of the patients had any vocal complaints in the preoperative period. $42 \%$ of patients had hoarseness 2 hours postoperatively which reduced to $18 \%$ in the 24 hours postoperative period. While $58 \%$ of patients had throat pain 2 hours postoperatively this reduced to $26 \%$ in the 24 hours postoperatively. Similarly, $8 \%$ of patients had vocal fatigue, $24 \%$ had throat clearing, and $16 \%$ had globus pharyngeus in the immediate 2 hours postoperative period, while it came back to levels of $12 \%, 14 \%$, and $10 \%$ in the 24 hours postoperative period, respectively (Fig. 1).

Vocal symptoms two hours after surgery was also correlated with the number of attempts at intubation, ET cuff volume, mean cuff pressure, size of the tube, duration of anesthesia and extubation quality. Overall, amongst the endotracheal tube related parameters, the number of intubation attempts at intubation were associated with vocal fatigue ( $p$ value 0.041 ) (Fig. 2 ), ET cuff volume with vocal fatigue ( $p$ value 0.037 ) (Fig. 3 ) and mean cuff pressure with throat clearing ( $p$ value 0.030 ) (Fig. 4).

With respect to the acoustic parameters, no significant change was noted in their values over a period of 24 hours (Table 2).

\section{Discussion}

The respiratory, neuromuscular, and to a little extent the endocrine system works in coordination for the production of voice. For human beings, the source for the production of sound is pulmonary air, which while passing through the infraglottic tract produces vibrations of vocal folds. The supraglottic tract and muscles of articulation are responsible for providing the characteristic voice quality of each individual. Orotracheal intubation can causing physical and structural changes in vocal folds and supraglottic

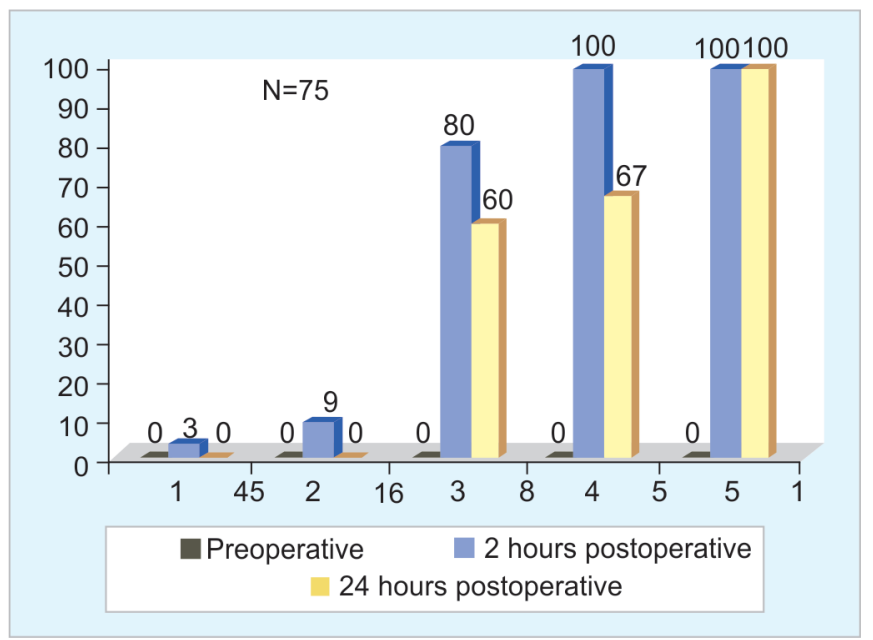

Fig. 2: Relationship of vocal fatigue with increase in number of intubation attempts (on $x$-axis $=$ number of intubation attempts, on $y$-axis = percentage of patients developing vocal fatigue. The values in box are number of patients) 


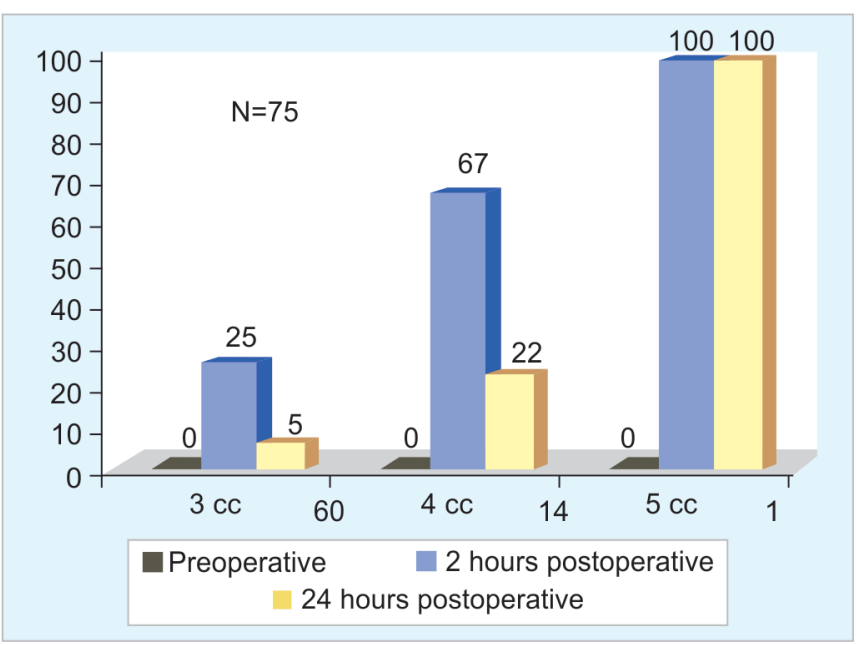

Fig. 3: Relationship of vocal fatigue with increase in ET cuff volume (on $x$-axis $=$ ET cuff volume, on $y$-axis = percentage of patients developing vocal fatigue. The values in box are number of patients)

Table 2: Mean values of acoustic parameters

\begin{tabular}{|c|c|c|c|}
\hline & Preoperative & $\begin{array}{l}2 \text { hours } \\
\text { postoperative }\end{array}$ & $\begin{array}{l}24 \text { hours } \\
\text { postoperative }\end{array}$ \\
\hline $\begin{array}{l}\text { Maximum phonation } \\
\text { time (seconds) }\end{array}$ & 13 & 11.4 & 12 \\
\hline $\begin{array}{l}\text { Average fundamental } \\
\text { frequency }(\mathrm{Hz})\end{array}$ & 234 & 221.32 & 246.49 \\
\hline Shimmer (\%) & 3.48 & 3.96 & 3.86 \\
\hline $\begin{array}{l}\text { Harmonic noise ratio } \\
\text { (dB) }\end{array}$ & 16 & 15.2 & 15.35 \\
\hline Jitter (\%) & 0.29 & 0.43 & 0.43 \\
\hline
\end{tabular}

tract and this subsequently can affect voice and phonatory behavior. ${ }^{5}$ Anesthetic gases and medications such as atropine, cause dehydration of the laryngeal mucosa, and can result in an increase in the vocal fold viscosity and impaired vibration. ${ }^{6-8}$ The incidence of laryngeal trauma ranged between $6.3 \%$ and $80 \% .{ }^{9,10}$

The extent of trauma can range from mere edema of the vocal fold, to vocal fold paresis, hematoma, lacerations, and granuloma formation. The trauma can occur while inserting the endotracheal tube, during the intubation, or while extubating. ${ }^{11-15}$ Consequently, such as the size of the tube, size of the larynx, cough pressure, and duration of anesthesia, are important in the interpretation of vocal symptoms postoperatively. In our study, indicated a close association between mean cuff pressure and throat clearing. The value of the mean cuff pressure was significantly greater in those who had increased throat clearing 2 hours after extubation than those otherwise. Likewise, vocal fatigue increased as the cuff volume and the number of attempts of intubation increased.

Voice quality can be affected by the changes in the respiratory and neuromuscular systems, such as musculoskeletal tenderness of intercostal muscles will cause pain during phonation affecting the voice quality. In our study, the most common vocal symptoms postextubation were throat pain and hoarseness, and to lesser extent were throat clearing, globus pharyngeus, and vocal fatigue.

For the acoustic parameters, review of literature showing the studies conducted by Horii and Fuller, ${ }^{16}$ Gleeson and Fourcin, ${ }^{17}$ Yonick et al. ${ }^{18}$ showed a significant decrease in mean fundamental frequency with a significant increase in shimmer and jitter.

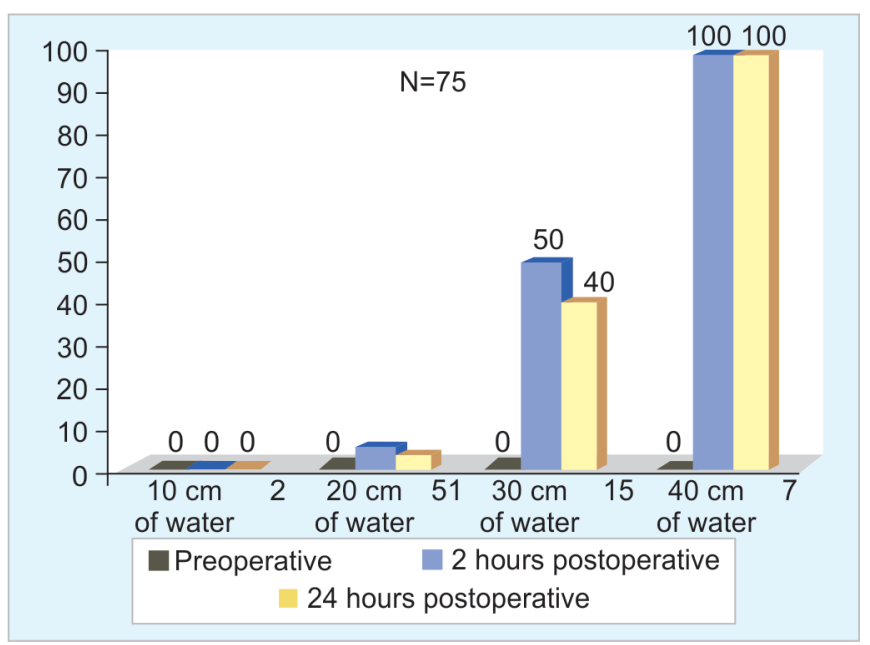

Fig. 4: Relationship of throat clearing with increase in mean cuff pressure (on $x$-axis $=$ mean cuff pressure, on $y$-axis = percentage of patients

Our study having 75 patients, which is one of the largest studies undertaken has shown no significant changes in the acoustic parameters over a period of 24 hours' time postextubation. Very few acoustic analysis studies ${ }^{16-18}$ have looked at acoustic variables before intubation and within 24 hours postextubation. Our study had a maximum number of patients and we had analyzed the association between endotracheal tube size and mean cuff pressure; however after that, we have not found any significant association between these two factors.

The findings in our study showed a significant association between ET cuff volume and the number of intubation attempts with vocal fatigue, also a significant association was present between mean cuff pressure and postoperative throat clearing. None of the acoustic parameters showed any significant changes over a period of 24 hours postextubation.

\section{Conclusion}

The endotracheal tube parameters, mean cuff pressure, and ET cuff volume are the most important variables that are associated with the increase in vocal symptoms. An increase in the value of these parameters is associated with more postoperative discomfort.

\section{Compliance with Ethical Standards}

- Written, informed, and valid consent was taken from all patients in the study.

- The study complies with the respective ethical standards of the institute.

\section{References}

1. McGovern FH, Fitz-Hugh GS, Edgemon LJ. The hazards of endotracheal intubation. Ann Otol, Rhinol Laryngol 1981;80(4):556. DOI: $10.1177 / 000348947108000419$.

2. Hedden M, Ersoz CJ, Donnelly HW, et al. Laryngotracheal damage after prolonged use of orotracheal tubes in adults. JAMA Otolaryngol 1977;207:703.

3. Weymuller E, Bishop M. Problems associated with prolonged intubation in the geriatric patient. Otolaryngolog Clin N Am 1990;23(6):1057-1074. DOI: 10.1016/S0030-6665(20)31189-0. 
4. Huang $\mathrm{H}-\mathrm{H}$, Lee M-S, Shih Y-L, et al. Modified mallampati classification as a clinical predictor of peroral esophagogastroduodenoscopy tolerance. BMC Gastroenterol 2011;11(1):12. DOI: 10.1186/1471-230X11-12.

5. Hamdan AL, Sibai A, Rameh C, et al. Short-term effects of endotracheal intubation on voice. J Voice Elsevier 2007;21(6):762-768. DOI: 10.1016/j.jvoice.2006.06.003.

6. Beckford NS, Mayo R, Wilkinson III A, et al. Effects of short endotracheal intubation on vocal function. Laryngoscope 1990;100(4):331-336. DOI: 10.1288/00005537-199004000-00001.

7. Finkelhor BK, Titze IR, Durham PL. The effect of viscosity changes in the vocal folds on the range of oscillation. J Voice 1988;1(4):320-325. DOI: 10.1016/S0892-1997(88)80005-5.

8. Bless D, Shaikh A, The effect of atropine on voice production. Presented at: State Medical Society of Otolaryngology, Milwaukee, WI, 1986.

9. Alessi D, Hanson D, Berci G. Bedside videolaryngoscopic assessment of intubation trauma. Ann Otol, Rhinol Laryngol 1989;98(8):586-590. DOI: $10.1177 / 000348948909800803$.

10. Preschel U, Eysholdt U. Kurzzeit-Veranderungen an Kehlkopf und Stimme nach Intubation. Laryngol Rhinol Otol (Stuttg) 1993;72(93):7. DOI: 10.1055/s-2007-997863.
11. Bishop M. Mechanisms of laryngotracheal injury following prolonged tracheal intubation. Chest 1989;96(1):185-186. DOI: 10.1378/ chest.96.1.185.

12. Colice G, Stukel T, Dain B. Laryngeal complications of prolonged intubation. Chest 1989;96(4):877-884. DOI: 10.1378/chest.96.4.877.

13. Weymuller E, Bishop M, Fink B, et al. Quantification of intralaryngeal pressure exerted by endotracheal tubes. Ann Otol, Rhinol Laryngol 1983;92(5):444-447. DOI: 10.1177/000348948309200506.

14. Weymuller E. Laryngeal injury from prolonged endotracheal intubation. Laryngoscope 1988;98(suppl 45):1-15. DOI: 10.1288/00005537-198808001-00001.

15. Leonard R, Senders C, Charpied G. Effects of long term intubation on vocal fold mucosa in dogs. J Voice 1992;6(1):86-93. DOI: 10.1016/ S0892-1997(05)80012-8.

16. Horii Y, Fuller B. Selected acoustic characteristics of voices before intubation and after extubation. J Speech Lang Hear Res 1990;33(3):505-510. DOI: 10.1044/jshr.3303.505.

17. Gleeson MJ, Fourcin AJ. Clinical analysis of laryngeal trauma secondary to intubation. J Royal Soc Med 1983;76(11):928. DOI: 10.1177/014107688307601108.

18. Yonick T, Reich A, Minifie F, et al. Acoustical effects of endotracheal intubation. J Speech Hear Disord 1990;55(3):427-433. DOI: 10.1044/ jshd.5503.427. 